\title{
Behaviour and performance of suckling gilts and their piglets in single housing with different fixation times
}

\author{
Ralf Wassmuth $^{1}$, Christoph Biestmann ${ }^{2}$, and Heiko Janssen ${ }^{2}$ \\ ${ }^{1}$ University of Applied Sciences, Am Kruempel 31, 49090 Osnabrück, Germany \\ ${ }^{2}$ Chamber of Agriculture Lower Saxony, Mars-la-Tour-Str. 6, 26121 Oldenburg, Germany
}

Correspondence to: Ralf Wassmuth (r.wassmuth@hs-osnabrueck.de)

Received: 25 October 2016 - Revised: 31 March 2017 - Accepted: 6 April 2017 - Published: 3 May 2017

\begin{abstract}
The objective was to evaluate suckling performance and behaviour traits of gilts and piglets in two different single-housing farrowing systems under practical conditions. Performance data of 70 crossbred gilts and their 842 piglets were collected. The behavioural observation included 17 gilts and 211 piglets. Gilts of the control group (full-time crating, FTC) were fixed during farrowing and suckling (Pro Dromi ${ }^{\circledR} 1$ ), and in the experimental group (short-time crating, STC) gilts were fixed for 6 days postpartum (p.p.) only (Pro Dromi ${ }^{\circledR} 1.5$ ). Six farrowing crates were included in each group, and six replications were carried out. Performance data were collected and gilts' and piglets' behaviour was observed with 10 min scan samples and categorized by standing, walking (only in STC), sitting and lying (side and belly). The management and the housing systems were in accordance with the Tierschutz-Nutztierhaltungsverordnung (TierSchNutztV, 2017). No significant $(p>0.05)$ differences between FTC and STC were found in piglets born alive (13.2 and 13.9, respectively), loss of piglets (1.4 and 1.55, respectively) and weaned piglets including cross-fostering (12.0 and 12.4, respectively). Piglet loss due to crushing was 0.6 (FTC) and 0.64 (STC), with no significant difference ( $p>0.05)$. Overall, $82.5 \%$ of all piglets killed due to crushing were lost from farrowing to day 2 p.p. The daily gain of STC piglets was significantly higher than that of FTC piglets $(205 \mathrm{~g}$ vs. $199 \mathrm{~g}$, respectively; $p<0.05)$ during the suckling period ( 3 weeks). Concerning gilts' behaviour, significant differences $(p \leq 0.05)$ were found in sitting duration only (FTC $5.8 \%$ and STC $4.0 \%$, respectively). FTC piglets spent more time lying, sitting and standing (7.4\% vs. $4.4 \%, 0.5 \%$ vs. $0.4 \%, 9.6 \%$ vs. $8.4 \%$, respectively; $p \leq 0.05)$. The reason could be the higher acceptance of the piglet nest in STC.

It was possible to conclude that gilts' welfare was improved by STC compared to FTC, and farrowing crates with loose single housing did not lead to higher piglet loss in the suckling period. An earlier end of the fixation period of the gilt at day 2 or 3 p.p. should be tested.
\end{abstract}

\section{Introduction}

During gestation sows must have the opportunity to move freely in a group of companions according to German legislation (TierSchNutztV, 2017). But in the suckling period sows are still kept on their own and full time in crates. This is not in accordance with a sow's behaviour under natural conditions. Sows live in a herd and leave the group approximately $24 \mathrm{~h}$ before farrowing (Jensen, 1986). On average 10 days postpartum (p.p.), sows return together with their piglets to the group and mix with it (Jensen and Redbo, 1987; Pitts et al.,
2000). Hence, single housing is in accordance with the needs of a sow around farrowing (Von Borell et al., 2002), but fixation in crates during the whole suckling period is not related to sows' welfare (Baxter et al., 2011). Hence, short-time crating (STC) could be a possible alternative to the present commercial practice of full-time crating (FTC) (Bünger, 2002; Weber et al., 2009).

Studies from Bohnenkamp et al. (2013) showed that suckling duration was similar in single and group housing. But other studies concluded that loose single housing or even group housing led to higher piglet loss due to crushing 
(Damm et al., 2005; Danholt et al., 2011; D'Eath, 2005; Maletinska and Spinka, 2001).

The aim of the present study was to evaluate suckling performance and behaviour of gilts and piglets in two different single-housing farrowing systems under practical conditions.

\section{Material and methods}

\subsection{Animals and housing}

The present investigation was performed in a newly built barn for 550 sows in the northern part of Germany, and it was not organized according to the rules of organic farming. The trial period lasted from February to May 2015, and it was possible to include BHZP (Bundes Hybrid Zucht Programm) Viktoria gilts mated to db77 boars. The gilts of the control group experienced FTC, which means conventional single housing. It was possible to include six farrowing crates, and gilts were fixated from $48 \mathrm{~h}$ prior to farrowing till weaning (Pro Dromi ${ }^{\circledR}$ 1). In the trial group, STC was practised and the gilts were fixated from $48 \mathrm{~h}$ prior to farrowing till the sixth day of suckling (Pro Dromi ${ }^{\circledR}$ 1.5). Six farrowing crates were a part of the investigation.

The single pens were identical in construction with an area of $6.5 \mathrm{~m}^{2}$ in total. The moving area of a gilt was $3.3 \mathrm{~m}^{2}$ (STC) and $1.3 \mathrm{~m}^{2}$ (FTC), respectively. In FTC and STC, six experiments each were conducted, and gilts entered the pens 5 days before farrowing; for 3 days they were not fixated and could explore the pen. In each pen, a jute bag $(1.2 \mathrm{~m} \times 0.6 \mathrm{~m})$ was provided to allow nest-building behaviour. During the first few sow feeding times, piglets were fixated in their nest to reduce loss due to crushing. Cross-fostering was done within FTC and STC as far as possible.

The housing systems and the management used in the present study were in accordance with the TierschutzNutztierhaltungsverordnung (TierSchNutztV, 2017).

\subsection{Recorded traits}

It was possible to analyse performance data of 70 gilts (first parity) and 842 piglets. Behavioural observations of 17 gilts and 211 piglets were performed.

Birth weight was measured 1 day after the main farrowing day and at the end of the first and second week of suckling. The final weight was recorded at day 18 p.p.

Behavioural parameters were recorded on video (Mobotix, 2017) with the scan sampling method (Hoy, 2009) on day $-1,0$ (farrowing), $+1,+5,+7$ and +16 . Videotapes were analysed with the instantaneous sampling (Hoy, 2009) method and an interval of $10 \mathrm{~min}$.

\subsection{Statistical analysis}

Statistical analysis was performed with the statistical software package IBM SPSS, Version 22.0 (IBM Corp., 2013).
Table 1. Mean (SD as index; minimum and maximum in parenthesis) for fertility traits of gilts across the two housing systems.

\begin{tabular}{lll}
\hline Trait & FTC & STC \\
\hline Number of gilts/farrows $(n)$ & 37 & 33 \\
Piglets born alive $(n)$ & $13.2_{4.0}(3-20)$ & $13.9_{3.6}(4-21)$ \\
Piglets born dead $(n)$ & $0.9_{1.4}(0-6)$ & $1.1_{1.3}(0-5)$ \\
Loss of piglets $(n)$ & $1.4_{1.4}(0-4)$ & $1.6_{1.4}(0-5)$ \\
Loss of piglets due to crushing $(n)$ & $0.66_{0.9}(0-3)$ & $0.6_{0.9}(0-3)$ \\
Loss of piglets $(\%)$ & $9.89 .3(0-28.6)$ & $10.29 .0(0-29.4)$ \\
\hline
\end{tabular}

The statistical model of the piglets' performance traits and of behavioural observations of piglets and gilts included fixed effects as shown below. The model of the traits of gilts performance obtained the fixed effect of the housing system only.

$Y_{i j k l}=\mu+H_{i}+B_{j}+S_{k}+b\left(W_{i j k l}-\bar{W}\right)+e_{i j k l}$,

where $Y_{i j k l}$ is observation, $\mu$ is the sample mean, $H_{i}$ is the fixed effect of housing system (FTC, STC), $B_{j}$ is the fixed effect of the batch (1 to 6), $S_{k}$ is the fixed effect of the piglets sex (male, female), $b\left(W_{i j k l}-\bar{W}\right)$ is the linear covariate of piglets birth weight and $e_{i j k l}$ is the residual random error.

\section{Results}

As shown in Table 1 the number of piglets born alive did not differ between FTC and STC, with 13.2 and 13.9, respectively. About one piglet was born dead per farrow, and the loss of piglets was low, with 1.4 in FTC and 1.6 in STC. The percentage of piglet loss due to crushing was the same in both systems and the proportion of lost piglets did not vary significantly (between 9.8 (FTC) and 10.2 (STC)). In STC only 1 out of a total of 21 piglets killed due to crushing were lost after the sixth day of suckling, the last day of gilts' fixation.

In STC, birth weight was lower than in FTC, but there was no difference in live weight at the 18th day p.p. between both housing systems (Table 2). Because of a significantly higher daily gain in week 2 and 3, STC piglets had a significantly higher daily gain during the suckling period with $205 \mathrm{~g}$ compared with FTC piglets reaching $199 \mathrm{~g}$.

Focusing on the lying behaviour, no significant differences were found between FTC and STC (Table 3). Gilts were lying on their side $57 \%$ (FTC) and $55.9 \%$ (STC) and on their belly $22.5 \%$ (FTC) and $23.4 \%$ (STC) of the total observation time. In FTC gilts spent a higher time period sitting (5.8\%) than gilts in STC (4.0\%). The difference was statistically significant. Neither in standing nor in suckling behaviour were significant differences found between the two systems (Table 3).

Piglets' behaviour differed between the two systems as shown in Table 4. FTC piglets showed significantly higher lying, sitting and standing frequencies. STC piglets spent significantly more time in their nest $(61.6 \%)$ than piglets in FTC $(55.9 \%)$. The observed differences in suckling behaviour between FTC and STC were not significant (Table 4). 
Table 2. LSQ (least-square) mean (SE as index; minimum and maximum in parenthesis) for growth traits of piglets across the two housing systems.

\begin{tabular}{lll}
\hline Trait & FTC & STC \\
\hline Number of piglets $(n)$ & 432 & 410 \\
Birth weight $(\mathrm{kg})$ & $1.35_{0.015}^{\mathrm{a}}(0.56-2.64)$ & $1.31_{0.016}^{\mathrm{b}}(0.62-2.54)$ \\
Live weight $(\mathrm{kg}), 18$ th day p.p. & $4.71_{0.030}(1.76-7.48)$ & $4.77_{0.031}(1.55-7.93)$ \\
Daily gain $\left(\mathrm{g} \mathrm{day}^{-1}\right)$, first week p.p. & $152_{2.3}(-53-358)$ & $153_{2.4}(-100-333)$ \\
Daily gain $\left(\mathrm{g} \mathrm{day}^{-1}\right)$, second week p.p. & $212_{2.1}^{\mathrm{a}}(36-360)$ & $223_{2.1}^{\mathrm{b}}(34-423)$ \\
Daily gain $\left(\mathrm{g} \mathrm{day}^{-1}\right)$, third week p.p. & $214_{2.6}^{\mathrm{a}}(-2-408)$ & $225_{2.6}^{\mathrm{b}}(4-436)$ \\
Total daily gain $\left(\mathrm{g} \mathrm{day}^{-1}\right)$ & $199_{1.7}^{\mathrm{a}}(46-329)$ & $205_{1.8}^{\mathrm{b}}(32-344)$ \\
\hline
\end{tabular}

a,b Significant differences $(p \leq 0.05)$.

Table 3. LSQ mean (SE as index) for behaviour of gilts across the two housing systems.

\begin{tabular}{lll}
\hline Trait & FTC & STC \\
\hline Number of gilts $(n)$ & 8 & 9 \\
Lying (side, \%) & $57.0_{1.85}$ & $55.9_{1.72}$ \\
Lying (belly, \%) & $22.5_{1.45}$ & $23.4_{1.35}$ \\
Sitting (\%) & $5.8_{0.56}^{\mathrm{a}}$ & $4.0_{0.52}^{\mathrm{b}}$ \\
Standing (\%) & $14.7_{1.00}$ & $14.8_{0.92}$ \\
Walking (\%) & - & 1.9 \\
Suckling (\%) & $29.8_{2.05}$ & $28.3_{1.90}$ \\
\hline a,b Significant differences $(p \leq 0.05)$. &
\end{tabular}

\section{Discussion}

The investigation took place in a newly built barn with a capacity of 550 sows, and it was not organized according to the rules of organic farming. So the circumstances differed from the usual ones when short-time crating in single housing or even group housing during farrowing and suckling was practised.

The number of piglets born alive in the present study was 13.2 and 13.9 and was a bit higher than the number of 13.0 observed in German commercial herds (ZDS, 2013). The total loss was 9.8 and $10.2 \%$ and was lower than reported in German commercial herds (14.5\%; ZDS, 2013). Baumgartner (2011) showed a live-born piglet mortality between 12.6 and $17.2 \%$ in eight European countries (CH, DK, GE, NL, SE, UK, NO, AT). Hence, it was possible to conclude that the circumstances of the present investigation represented well-managed commercial herds.

The loss of piglets due to crushing was less than half of all loss, and it was the same in both systems (FTC, STC). Jungbluth et al. (2005) concluded that $60 \%$ of all loss was caused by crushing. With $4.2 \%$ (FTC) and $4.3 \%$ (STC) crushed piglets in similar systems, Soede et al. (2014) had nearly the same results as the present study. By contrast with these results, Weber et al. (2007) found higher loss due to crushing in loose single housing (5.4\%) than in FTC (4.5\%). Even
Table 4. LSQ mean (SE as index) for behaviour of piglets across the two housing systems.

\begin{tabular}{lll}
\hline Trait & FTC & STC \\
\hline Number of piglets $(n)$ & 95 & 116 \\
Lying (\%) & $7.4_{1.04}^{\mathrm{a}}$ & $4.4_{0.96}^{\mathrm{b}}$ \\
Sitting (\%) & $0.5_{0.05}^{\mathrm{a}}$ & $0.4_{0.04}^{\mathrm{b}}$ \\
Standing (\%) & $9.6_{0.37}^{\mathrm{a}}$ & $8.4_{0.34}^{\mathrm{b}}$ \\
Suckling (\%) & $26.6_{1.55}$ & $25.2_{1.43}$ \\
Time spending in the nest (\%) & $55.9_{2.08}^{\mathrm{a}}$ & $61.6_{1.93}^{\mathrm{b}}$ \\
\hline
\end{tabular}

a,b Significant differences $(p \leq 0.05)$.

Damm et al. (2005), Danholt et al. (2011), D'Eath (2005), and Maletinska and Spinka (2001) found higher loss due to crushing in loose single and even group housing.

One reason for the low crushing loss in STC in the present study could be that piglets spent about $60 \%$ of the observed time in the nest. This could be due to the construction of the Pro Dromi ${ }^{\circledR}$ system were the piglets' nest was located in front of the head of the gilt and piglets could keep contact with their mother. Further, the jute bag used by the gilt to show nesting behaviour was put into the piglets' nest which made it more attractive for the piglets. Possibly this management led to a strong mother offspring bond.

Only 1 of 21 piglets was lost after ending the fixation of the gilt at day 6 p.p. This led to the conclusion that the ending of fixation at an earlier stage of suckling must not necessarily lead to higher loss. Research should be intensified to optimize STC systems.

In the present study suckling frequencies were a bit lower in STC, but the difference was not significant. The study of Bohnenkamp et al. (2013) confirmed this result because they found no differences in suckling frequencies between FTC and STC. Although the suckling frequencies were similar from a statistical point of view and the birth weight was higher in FTC, in the second and third week the daily gain of piglets was significantly higher in STC compared to FTC. This is in accordance with Soede et al. (2014), who found 
a significantly higher daily gain in STC $\left(250 \mathrm{~g} \mathrm{day}^{-1}\right)$ compared to FTC $\left(237 \mathrm{~g} \mathrm{day}^{-1}\right)$. It was possible to conclude that the housing system had an effect on daily gain.

Hence, piglets' welfare was not negatively influenced by STC, where the gilt has more opportunities to move than in FTC. Gilts showed sitting behaviour less often, which might lead to the conclusion that gilts' welfare was improved by STC compared to FTC.

\section{Conclusions}

We conclude the following:

1. The loss of piglets due to crushing was not significantly higher in STC compared to FTC.

2. The daily gain of piglets was slightly higher when gilts were fixated for a short time compared to full-time crating.

3. Sitting behaviour occurred more often in FTC, and it was possible to conclude that gilts' welfare was adversely influenced.

4. No differences between FTC and STC were found in suckling frequency, and a higher moving activity of piglets could be observed in STC.

Data availability. Data are available on request from the corresponding author.

Competing interests. The authors declare that they have no conflict of interest.

Edited by: M. Mielenz

Reviewed by: two anonymous referees

\section{References}

Baumgartner, J.: Pig industry in $\mathrm{CH}, \mathrm{CZ}, \mathrm{DE}, \mathrm{DK}, \mathrm{NL}$, NO, SE, UK, AT and EU, Report of the Free Farrowing Workshop Vienna 2011, 8-9 December, 2011, Vienna, Austria, University of Veterinary Medicine Vienna Austria, 3-7, http://www.vetmeduni.ac.at/fileadmin/_migrated/content_ uploads/FFWV_2011-Report.pdf (last access: May 2017), 2011.

Baxter, E. M., Lawrence, A. B., and Edwards, S. A.: Alternative farrowing systems: design criteria for farrowing systems based on the biological needs of sows and piglets, Animal, 5, 580-600, 2011.

Bohnenkamp, A.-L., Meyer, C., Müller, K., and Krieter, J.: Group housing with electronically controlled crates for lactating sows. Effect on farrowing, suckling and activity behavior and piglets, Appl. Anim. Behav. Sci., 145, 37-43, 2013.

Bünger, B.: Einflüsse der Haltungsbedingungen von ferkelnden und ferkelführenden Sauen auf die Entwicklung der Ferkel: Eigene Studien und eine Bewertung der Literatur, Dtsch. Tierärztl. Wschr., 109, 277-289, 2002.
Damm, B. I., Forkman, B., and Pedersen, L. J.: Lying down and rolling behaviour in sows in relation to piglet crushing, Appl. Anim. Behav. Sci., 90, 3-20, 2005.

Danholt, L., Mousten, V. A., Nielsen, M. B. F., and Kristensen, A. R.: Rolling behaviour of sows in relation to piglet crushing on sloped versus level floor pens, Livestock Sci., 141, 59-68, 2011.

D'Eath, R. B.: Socialising piglets before weaning improves social hierarchy formation when pigs are mixed post-weaning, Appl. Anim. Behav. Sci., 93, 199-211, 2005.

Hoy, S. (Ed.): Methoden der Nutztierethologie, in: Nutztierethologie, Verlag Eugen Ulmer, Stuttgart, 2009.

IBM Corp: Released 2013, IBM SPSS Statistics for Windows, Version 22.0, IBM Corp., Armonk, NY, 2013.

Jensen, P.: Observations on the maternal behaviour of free-ranging domestic pigs, Appl. Anim. Behav. Sci., 16, 131-142, 1986.

Jensen, P. and Redbo, I.: Behaviour during nest leaving in freeranging domestic pigs, Appl. Anim. Behav. Sci., 18, 355-362, 1987.

Jungbluth, T., Büscher, W., and Krause, T.: Technik Tierhaltung (Kapitel 6 - Verfahren der Schweinehaltung), Verlag Eugen Ulmer, Stuttgart, 2005.

Maletinska, J. and Spinka, M.: Cross-suckling and nursing synchronisation in group housed lactating sows, Appl. Anim. Behav. Sci., 75, 17-32, 2001.

Mobotix: Handbuch zur Kamera 'M25M Allround', http:// mobotix.com/ger_DE/Produkte/Outdoor-Kameras, last access: May 2017.

Pitts, A. D., Weary, D. M., Pajor, E. A., and Fraser, D.: Mixing at young ages reduces fighting in unacquainted domestic pigs, Appl. Anim. Behav. Sci., 68, 191-197, 2000.

Soede, N., Schuttert, M., and Hoofs, A.: Resultate Forschung VIC Sterksel und Implementation in die Praxis, in: Vortrag auf dem Pro Dromi ${ }^{\circledR}$ Symposium, 14 February 2014, Arnheim, the Netherlands, http://www.prodromi.nl/afbeeldingen/ Symposium-Pro-Dromi-Day.pdf (last access: May 2017), 2014.

TierSchNutztV: Tierschutznutztierhaltungsverordnung, veröffentlicht im BGB1, Teil I/2006, S. 2043, 22 August 2006, zuletzt geändert durch Artikel 1 der Verordnung veröffentlicht im BGBl, I/2014, S. 94, 5 February 2014, http://www.gesetze-im-internet. de/bundesrecht/tierschnutztv/gesamt.pdf, last access: May 2017.

Von Borell, E., Von Lengerken, G., and Rudovsky, A.: Tiergerechte Haltung von Schweinen - Grundlegende Anforderungen, in: Umwelt- und tiergerechte Haltung von Nutz,- Heim-, und Begleittieren, edited by: Methling, W. and Unshelm, J., Parey Buchverlag, Berlin, 2002.

Weber, R., Keil, N. M., Fehr, M., and Horat, R.: Praxisvergleich der Reproduktionsleistungen zwischen Abferkelbuchten mit und ohne Kastenständen, in: Tagungsband zur 8 Tagung Bau, Technik und Umwelt 2007 in der landwirtschaftlichen Nutztierhaltung, 8-10 October 2007, Kuratorium für Technik und Bauwesen in der Landwirtschaft, Bonn, Darmstadt, 2007.

Weber, R., Keil, N. M., Fehr, M., and Horat, R.: Factors affecting piglet mortality in loose farrowing systems on commercial farms, Livestock Sci., 124, 216-222, 2009.

ZDS: Zahlen aus der Deutschen Schweineproduktion 2012, 2013 Edn., Zentralverband der Deutschen Schweineproduktion e.V. (ZDS), Bonn, 2013. 